\title{
Epidemiology of Bloodstream Candida spp. Infections Observed During a Surveillance Study Conducted in Spain
}

\author{
R. Cisterna, G. Ezpeleta and O. Tellería \\ Clinical Microbiology and Infection Control Department \\ Basurto Hospital, Avenida Montevideo - Bilbao \\ Spain
}

\section{Introduction}

Candida bloodstream infections (BSI) have become a major healthcare problem, specially in tertiary- care hospitals worldwide (Al-Jasser \& Elkhizzi, 2004, Almirante et al., 2005, AlonsoValle et al., 2003, Atunes et al., 2004 Asmundsdottir et al., 2002, Costa et al., 2000, Fraser et al., 1992, Garbino et al., 2002, Luzzati et al. 2000, Marchetti et al., 2004, Pappas et al., 2003, Viudes et al., 2002). Several risk factor identified among patients hospitalized for long periods such as the exposition to broad spectrum antimicrobial and/or immunosuppressive chemotherapy, parenteral nutrition, and invasive medical procedures have contributed to this fact (Blumberg et al., 2001, Fraser et al., 1992). Despite some improvements in fungal BSI diagnosis during last years, candidemia diagnosis remains difficult. Besides, following the data appeared in the classical study from Berenguer and colleagues, only $50 \%$ of patients with disseminated candidiasis will have positive blood cultures and even fewer will have an antemortem diagnosis (15\% to 40\%) (Berenguer et al., 1993). Therefore, invasive candidemia is not easy to diagnose, has an expensive treatment and finally is a serious, often lifethreatening infection (Girmenia et al., 1996, Messer et al., 2009).

Although the incidence of candidemia has increased steadily among hospitalized patients during the eighties and nineties, recent series suggest that This increase has stabilized, but with great variations between different geographical locations with similar socio-economical development even in the same continent. For instance, in The Netherlands an increasing incidence of candidemia has been reported during the period between eighties and nineties (Voss et al., 1996) but on the other hand, in a neighbouring country such as Switzerland the incidence of Candida BSI infections remained unchanged during the same period (Marchetti et al., 2004). Therefore, it seems that there are some differences in the epidemiology of candidemia between different countries.

Besides, in recent years, a trend towards increasing resistance to both traditional and more recently introduced antifungal agents has been observed amongst invasive Candida infections, underscoring the need for continuous surveillance to monitor trends in incidence, species distribution, and antifungal drug susceptibility profiles. 
The epidemiology of candidemia has been extensively studied in many countries and there are some large series published in this field (Alonso-Valle et al., 2003, Atunes et al., 2004, Banerjee et al., 1991, Colombo et al., 2006, Diekema et al., 2002, Kao et al., 1999, Messer et al., 2009, San Miguel et al., 2005, Silva et al., 2004, Tortorano et al., 2004, Trick et al., 2002). But, most of the data on candidemia in Spain until recent days are limited to retrospective reviews of medical records or observational studies conducted in a limited geographical area (Almirante et al., 2005, Alonso-Valle et al., 2003, Pemán et al., 2002, Pemán et al., 2011). Regarding the Spanish data available on antifungal resistance is often assessed by occasional surveys or reported in summaries of sporadically occurring cases of treatment failures. The purpose of such investigations is to monitor levels of susceptibility to different agents. However, long-term prospective studies of antifungal susceptibility have the advantage of eliminating a number of variable factors which may affect these assessments. Some of these factors include temporary changes in patterns of Invasive Candida infections (as stated before) and transient alterations in antifungal resistance due to special conditions (e.g. candidemia outbreaks in ICUs). Consequently, the epidemiological data about candidemia and its impact in the healthcare system is unknown, and no reliable nationwide data are available. In order to make a realistic global perspective of invasive Candida BSI, we designed a prospective laboratory-based surveillance study comprising 40 tertiary care hospitals across the country, to assess the incidence, species distribution, frequency of antifungal resistance, and risk factors for candidemia.

\section{Materials and methods}

\section{Study design}

A prospective laboratory-based surveillance was established to monitor the predominant Candida species and antifungal resistance patterns of nosocomial and community-acquired invasive Candida infections via a network of sentinel hospitals distributed by geographic location across the country.

The participating institutions include 40 medical centers which provide medical care either to adults and children in several medical specialties. Each participant hospital contributed prospectively clinical and epidemiological results (organism identification, date of isolation, hospital location, intrinsic and extrinsic risk factors for candidemia) on clinically significant consecutive blood culture isolates of Candida spp. (one isolate per patient) detected during the 12-month period from June, 2008 through June, 2009. All isolates were saved on agar slants and were sent on a trimestral basis to the Mycology Laboratory at Basurto Hospital for storage, further characterization and reference susceptibility testing.

\section{Clinical definitions}

Clinical and case definitions were according the NHSN (formerly NNISS) methodology. Statements defining a case and other clinical conditions are summarized in Table 1.

\section{Quality control measures of clinical data}

The clinical case report list of each hospital was compared with the isolates received at Basurto Hospital to perform the antifungal susceptibility in order to verify that neither cases nor isolates were missed. Audits of medical records to verify accuracy of data and completeness were performed on $25 \%$ of cases. 


\begin{tabular}{|ll|}
\hline Incident case of candidemia: & The incident isolation of Candida spp. from a blood culture. \\
New incident case of candidemia: & $\begin{array}{l}\text { An episode of candidemia occurring more than } 30 \text { days } \\
\text { after the initial incident isolation. }\end{array}$ \\
Breakthrough candidemia: & $\begin{array}{l}\text { The incident isolation of Candida spp. from a blood culture } \\
\text { from a patient receiving systemic antifungal therapy for }\end{array}$ \\
& $\begin{array}{l}\text { any reason. } \\
\text { Fever: }\end{array}$ \\
Neutropenia: & Peripheral body temperature equal or higher than $37.8^{\circ} \mathrm{C}$ \\
Adult patients: & An absolute neutrophil count of less than 500 cells $/ \mathrm{mm}^{3}$. \\
\end{tabular}

Table 1. Definitions according to NHSN (formerly NISS) used in this study

\section{In vitro susceptibility testing}

Antifungal susceptibility tests were performed by using the broth microdilution assay according to the methodology recommended by the CLSI (formerly known as NCCLS), document M27-A2 (NCCLS, 2002) using a microtiter plate. Each isolate was tested against different antifungal drugs at the indicated concentration range suggested in the CLSI document. Quality control (QC) was ensured by testing the CLSI recommended QC strains, C. krusei ATCC 6258, and C. parapsilosis ATCC 22019.The MIC endpoint for amphotericin B, azoles and echinocandins and interpretative MIC breakpoints for azoles and echinocandins were those suggested by the CLSI document M27-A2, but for the definition of the amphotericin B MIC breakpoints we used the values suggested from a previous study published by Nguyen et al. (Nguyen et al., 1998).

\section{Statistical analysis}

The numbers of admissions and patient-days were collected to calculate incidence rates. The incidence rate for each hospital was calculated as the number of candidemias per 1,000 admissions, whereas the overall incidence was determined using summed denominators of patient-days and admissions to calculate pooled mean rates. The data generated during the year of the surveillance on the different risk factors, underlying diseases, morbidity and mortality were recorded in a Microsoft Access 2003 (Microsoft Corporation, Redmond, WA) based case report database. Categorical data were analyzed using Chi-square or Fisher's exact tests as appropriate, and continuous variables were compared using the t-test or Wilcoxon test according to the significance of the normality test. Spearman rank-order correlation was used to measure the relationship between the MICs of fluconazole and voriconazole. We performed univariate and multivariate analysis of factors associated with candidemia caused by isolates with decreased susceptibility to fluconazole. Variables significant at $p$-values of less than 0.05 by univariate analysis were included in a multivariate model using a repeated measures logistic regression model (backward and forward). Data were analyzed using the SPSS 11.0.1 software (SPSS, Inc. Chicago, IL) and Stata 8.0 (Stata Corporation, Lenexa, TX).

\section{Distribution of Candida blodostream infections}

During the 12-month study period a total of 984 Candida BSIs were reported. The calculated overall incidence was 1.09 cases per 1,000 admissions, however the incidence rate changed a lot between the 40 centers enrolled in this study and ranged from 0.76 to 1.49 cases per 1,000 admissions. 
Among the invasive Candida BSIs, $45.3 \%$ occurred in patients in an medical service, $23.5 \%$ in patients hospitalized in an intensive care unit, $17.6 \%$ in patients in a surgical ward, $7.41 \%$ in a pediatric ward and finally $4.06 \%$ in other services. Most of the patients $(98.7 \%)$ were hospitalized and only nine of them were outpatients at the time of diagnosis.

Candidemia incidence was slightly higher in males $(64.02 \%$ of the case patients) and the global average age at the onset of the episode was 41 years with a median age was 53 years among adult patients and 7 months among children.

The frequency of BSIs due to the most frequently isolated species of Candida in the study sites are presented in Table 2.

\begin{tabular}{ccc} 
Species & No. $(\%)$ of cases & Range (in \%) between clinical settings \\
\hline C. albicans & $483(49.08 \%)$ & $27-54$ \\
C. parapsilosis & $204(20.73 \%)$ & $7-40$ \\
C. glabrata & $134(13.61 \%)$ & $2-14$ \\
C. tropicalis & $106(10.77 \%)$ & $16-29$ \\
C. krusei & $21(2.13 \%)$ & $0-9$ \\
Other species a & $36(3.65 \%)$ & $0-4$ \\
\hline
\end{tabular}

a Species with less than 10 isolates are included in this category. This category includes C. famata, C. lusitaniae, C. pelliculosa and Candida spp.

Table 2. Species distribution and incidence among 984 cases of candidemia detected during prospective sentinel surveillance in Spain from June 2008 to June 2009

Overall, the $49.08 \%$ of the cases were attributable to C. albicans, $20.73 \%$ were attributable to C. parapsilosis, $13.61 \%$ were attributable to C. glabrata, $10.77 \%$ were attributable to C. tropicalis, $2,13 \%$ to C. krusei and the rest of the cases $(3.65 \%)$ were attributable to other species. The distribution of Candida species among adult population was similar to the one found in pediatric cases, however, the distribution of species varied considerably when analyzed between centers as it has been reflected in the ranges specified in Table 2 . The species distribution among our study isolates is similar to that described by Pfaller et al. (Pfaller et al., 1998) in Latin America with data collected by the Sentry Antimicrobial Surveillance Program. As Pfaller and colleagues described previously, the proportion of species isolated varies considerably among medical centers beign unclear the reasons for such differences and they could be attributed to many different influences.

Table 3 summarizes the overall clinical characteristics and outcome of the 984 candidemia cases identified.

At the time of candidemia diagnosis, neoplasia was documented for 195 (19.84\%) patients, 35 of which $(17.94 \%)$ were affected with hematologic malignancies Prior surgery was recorded from $311(31.6 \%)$ patients (311 of a total of 984), being most of them abdominal surgeries (64\% of total surgical patients). Two third of the patients $(66.97 \%)$ had a central venous catheter and one quarter $(26.93 \%)$ of them were under mechanical ventilation. Neutropenia and dialysis were rare conditions which was only documented in only 35 case patients $(3.55 \%)$ and 12 patients $(1.21 \%)$ respectively. Invasive Candida spp. infection complications such as endocarditis or endophalmitis were infrequent and with 17 cases documented for the former complication ( $2 \%)$ and 3 patients for the later. 


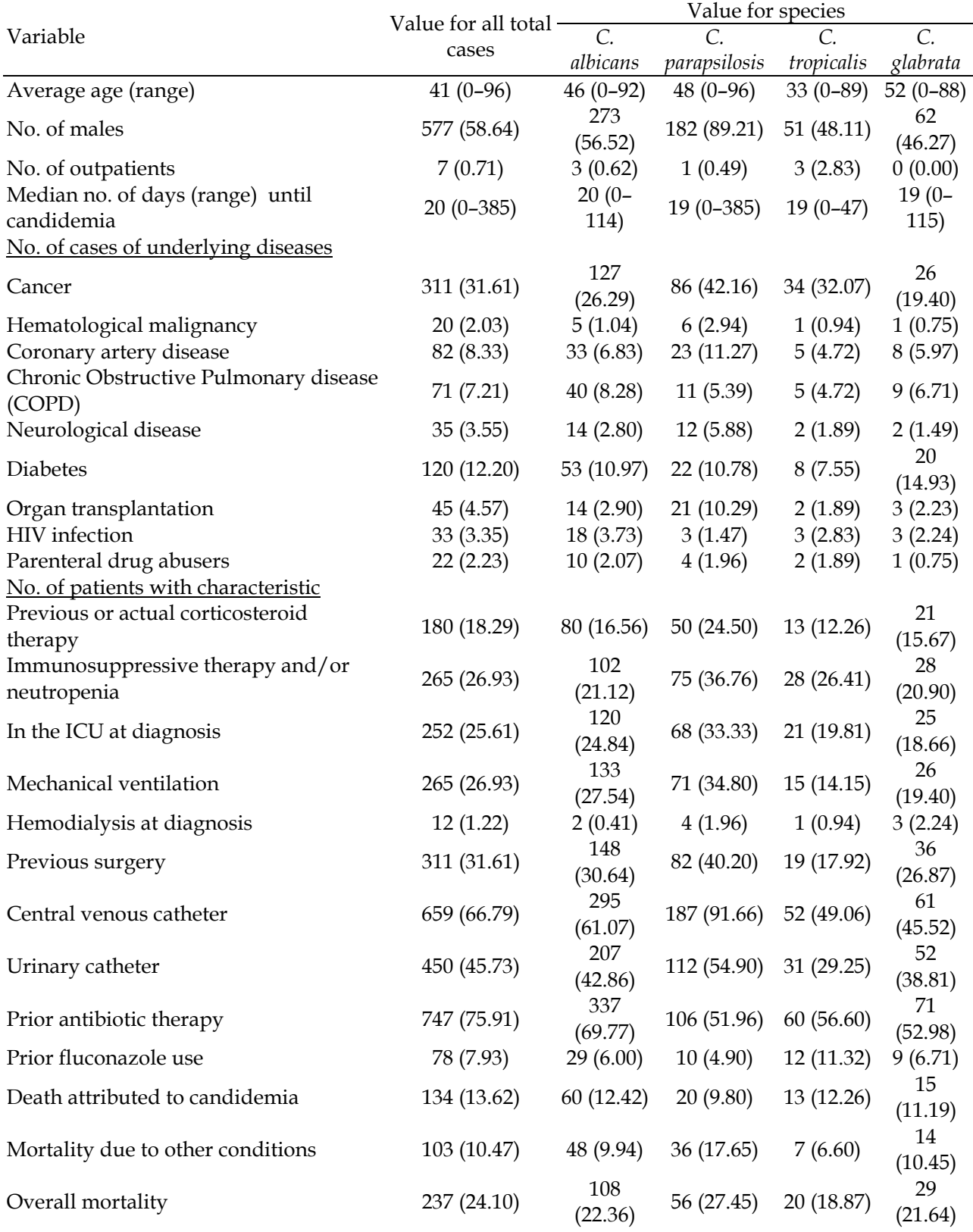

Table 3. Demographics, clinical characteristics, and mortality for Candida spp. BSI episodes identified during prospective sentinel surveillance conducted in Spain from June 2008 to June 2009. 
There were no statistically significant differences when the risk mentioned above were analyzed for the pediatric population of patients.

\section{Antifungal susceptibility}

In vitro susceptibility testing of the 984 BSI isolates of Candida species against amphotericin $\mathrm{B}$, fluconazole, voriconazole, caspofungin and anidulafungin revealed that when globally analyzed Candida strains causing BSI are rarely resistant to a wide number of antifungal agents. However, the resistance rates among the different species vary a lot as it can be shown on Table 4.

\begin{tabular}{|c|c|c|c|c|c|}
\hline \multirow[t]{2}{*}{ Species } & \multirow{2}{*}{$\begin{array}{c}\text { Antifungal } \\
\text { agent }\end{array}$} & \multicolumn{3}{|c|}{$\begin{array}{c}\mathrm{MIC} \\
(\mathrm{ug} / \mathrm{ml})\end{array}$} & \multirow[t]{2}{*}{$\begin{array}{c}\text { No. of resistant or SDD } \\
\text { isolates }\end{array}$} \\
\hline & & Range & $50 \%$ & $90 \%$ & \\
\hline \multirow[t]{5}{*}{ C. albicans (483) } & Amphotericin B & $\begin{array}{c}0.125- \\
1.0\end{array}$ & 0.5 & 1.0 & $0(0.00)$ \\
\hline & Fluconazole & $0.125-64$ & 0.5 & 2.0 & $10(2.07)$ \\
\hline & Voriconazole & $<0.03-4$ & 0.03 & 0.03 & $5(1.04)^{\prime}$ \\
\hline & Caspofungin & $<0.03-4$ & 0.25 & 2.0 & $3(0.62)$ \\
\hline & Anidulafungin & $<0.03-2$ & 0.03 & 0.03 & $0(0.00)$ \\
\hline \multirow{5}{*}{$\begin{array}{c}\text { C. parapsilosis } \\
\text { (204) }\end{array}$} & Amphotericin B & $0.25-1.0$ & 1.0 & 1.0 & $0(0.00)$ \\
\hline & Fluconazole & $0.125-64$ & 0.5 & 4.0 & $11(5.39)^{\text {a }}$ \\
\hline & Voriconazole & $0.03-2$ & 0.03 & 0.125 & $3(1.47)^{b}$ \\
\hline & Caspofungin & $0.125-64$ & 1.0 & 2.0 & $12(5.88)$ \\
\hline & Anidulafungin & $0.03-64$ & 1.0 & 2.0 & $7(3.43)$ \\
\hline \multirow[t]{5}{*}{ C. glabrata (134) } & Amphotericin B & $0.25-1.0$ & 0.5 & 1.0 & $0(0.00)$ \\
\hline & Fluconazole & $1.0-64$ & 4.0 & 32 & $25(18.67)$ \\
\hline & Voriconazole & $0.03-4.0$ & 0.125 & 0.5 & $3(2.24)$ \\
\hline & Caspofungin & $0.03-0.5$ & 0.06 & 0.125 & $0(0.00)$ \\
\hline & Anidulafungin & $0.06-0.5$ & 0.06 & 0.125 & $0(0.00)$ \\
\hline \multirow[t]{5}{*}{ C. tropicalis (106) } & Amphotericin B & $\begin{array}{c}0.125- \\
1.0\end{array}$ & 0.5 & 1.0 & $0(0.00)$ \\
\hline & Fluconazole & $\begin{array}{c}0.25- \\
128\end{array}$ & 1 & 2 & $2(1.89)$ \\
\hline & Voriconazole & $0.03-8$ & 0.06 & 0.125 & $2(1.89)$ \\
\hline & Caspofungin & $0.03-0.5$ & 0.06 & 0.125 & $0(0.00)$ \\
\hline & Anidulafungin & $0.03-0.5$ & 0.03 & 0.125 & $0(0.00)$ \\
\hline \multirow[t]{5}{*}{ C. krusei (21) } & Amphotericin B & $\begin{array}{c}0.125- \\
2.0\end{array}$ & 0.25 & 0.75 & $0(0.00)$ \\
\hline & Fluconazole & $16-128$ & 4.0 & 8.0 & $21(100.00)$ \\
\hline & Voriconazole & $0.03-4.0$ & 0.25 & 1.0 & $2(9.52)$ \\
\hline & Caspofungin & $0.125-8$ & 0.125 & 1.0 & $1(4.76)$ \\
\hline & Anidulafungin & $0.03-8$ & 0.06 & 0.25 & $1(4.76)$ \\
\hline
\end{tabular}

a All the isolates except one exhibit decreased susceptibility (SDD) to fluconazole. ${ }^{b}$ All the isolates are SDD to voriconazole.

Table 4. Antifungal susceptibility test results for selected species of Candida isolated during prospective, sentinel surveillance in Spain from June 2008 to June 2009 
When we considered the C. glabrata isolates obtained during the study only the $81.33 \%$ of them were were susceptible to fluconazole and $97.76 \%$ were susceptible to voriconazole, but on the contrary, $97.93 \%$ and $98.96 \%$ of the isolates of C. albicans were susceptible to fluconazole and voriconazole respectively. The proportion of isolates that was resistant to the studied azole drugs was comparable with that observed in the other recently published studies. (Messer et al., 2009, Pemán et al., 2011).

The antifungal activities of voriconazole, fluconazole, amphotericin B, caspofungin and anidulafungin against the 984 Candida spp isolated during the study period are summarized in Table 4. Among the azole compounds, voriconazole was the most active drug overall with an MIC90 of $0.25 \mu \mathrm{g} / \mathrm{ml}$. Against C. albicans, C. parapsilosis and C. tropicalis isolates, voriconazole (MIC90 range $0.03-0.25 \mu \mathrm{g} / \mathrm{ml}$ ) was much more active than fluconazole (MIC90, 2-4). Although these differences in the drug activity, both azole compounds showed lower MICs for fluconazole and voriconazole for the species mentioned before when compared to C. glabrata and C. krusei isolates. Despite this good susceptibility profile, we found five Candida albicans isolates with a MIC greater than $4 \mu \mathrm{g} / \mathrm{ml}$ to voriconazole and two C. krusei isolates that had a voriconazole MIC of $2 \mathrm{ug} / \mathrm{ml}$. All these isolates were also resistant to fluconazole.

We found that there was a statistically significant moderate linear correlation between fluconazole and voriconazole MICs $(r=0.574 ; P \leq 0.01)$. having higher voriconazole MICs those isolates from patients who received fluconazole before the candidemia episode when compared to those without previous exposure to fluconazole (MIC90s of $0.25 \mu \mathrm{g} / \mathrm{ml}$ and $0.06 \mu \mathrm{g} / \mathrm{ml}$, respectively; $P \leq 0.05$

Table 5 summarize the risk factors we identified during the study with a candidemia episode due to an isolate with decreased susceptibility (SDD or resistant) to fluconazole using univariate statistical techniques.

No of isolates (\%) No. of isolates (\%) with decreased susceptible to susceptibility or resistant to $\quad \mathrm{P}$ - value fluconazole fluconazole

\begin{tabular}{lccc}
\hline Neoplasia & $27(2.95)$ & $6(8.70)$ & $\leq 0.01$ \\
Neutropenia & $37(4.04)$ & $11(15.94)$ & $\leq 0.01$ \\
Prior fluconazole use & $27(2.95)$ & $10(14.49)$ & $\leq 0.01$ \\
\hline
\end{tabular}

a Only statistically significant variables are summarized in the table

Table 5. Summary of univariate statistical analysis between fluconazole susceptible isolates vs. resistant or SDD ones

We found that this condition was associated with neoplasia (9\% versus $3 \%$; $P \leq 0.01$ ), current neutropenia $(16 \%$ versus $4 \% ; P \leq 0.01)$, and prior fluconazole use $(14 \%$ versus $3 \% ; P \leq 0.001)$. These independent factors identified using the univariate statistical approach, were analyzed more deeply using a repeated measures logistic regression model. We obtained significant results for neoplasia (odds ratio, 2.9; 95\% confidence interval, 1.4 to $5.9 ; P \leq 0.05$ ) and prior use of fluconazole (odds ratio, 3.8 ; $95 \%$ confidence interval, 1.7 to $8.2 ; P \leq 0.01$ ). (Table 6). 


\begin{tabular}{lccc} 
& Odds ratio & 95 percent confidence Limits & P - value \\
\hline Neoplasia & 2.9 & $1.4-5.9$ & $\leq 0.05$ \\
Prior fluconazole use & 3.8 & $1.7-8.2$ & $\leq 0.01$ \\
\hline
\end{tabular}

a Only statistically significant variables are summarized in the table.

Table 6. Summary of multivariate statistical analysis of risk factors for candidemia caused by fluconazole susceptible isolates vs. resistant or SDD ones a

Caspofungin and anidulafungin resistance was low (16 cases for caspofungin and 8 cases for anidulafungin) (Table 4). Despite this low rate of in vitro resistance to echinocandins of the isolates studied MICs from C. parapsilosis and C. guilliermondi were higher compared to the MIC obtained from other Candida spp. as it has been described in others studies.

\section{Antifungal treatment}

At the time of diagnosis and inclusion in this study, 122 case patients $(12.3 \%)$ were receiving a systemic antifungal agent and were considered breakthrough infections (fluconazole, 78 patients, amphotericin B, 31 patients, itraconazole and voriconazole, 3 patient each; and echinocandins, 5 patients). Although the reason for this high rate of breakthrough infections is not clear, it is possible that other factors besides the antifungal resistance have got a role in the explanation of this phenomenon. A deep analysis of these 122 cases showed that either the antifungal therapy duration or the election of the antifungal drug was inadequate. A total of 536 case patients (54.5\%) received antifungal therapy, started at a median of 3 days from the Candida isolation or onset of candidemia.

\section{Mortality}

The crude mortality rate was $24.10 \%$, but the mortality rate among children was significantly lower. (see Table 3) As it has been described in different studies published in the medical literature candidemia due to C. parapsilosis had a lower mortality rate than the rate due other Candida species (Morgan et al., 2005, Pappas et al., 2004, Pemán et al., 2002), but no statistically significant result when analyzing the death rate of patients infected by a susceptible isolate (54\%) or a less-susceptible isolate (SDD or resistant) (64\%) among patients who received fluconazole as treatment. $(P \leq 0.44)$.

\section{Discussion and remarks}

This prospective candidemia surveillance study represents one of the largest multicenter studies conducted in Spain and provide one of the most representative data on the epidemiology of candidemia to date. The first remarkable finding of our study was the higher incidence of candidemia than those reported from centers located in the Northern Hemisphere which ranged between 0.28 to 0.96 per 1,000 admissions (Banerjee et al., 1991, Doczi et al., 2002, Marchetti et al., 2002, Pfaller et al., 1998, Pfaller et al., 2004, Richet et al., 2002, Sandven et al., 1998, Tortorano et al., 2002, Tortorano et al., 2004) and including those published before in Spain (0.76 to 0.81 per 1,000 admissions) (Almirante et al., 2005, AlonsoValle et al., 2003, Pemán et al., 2002, Pemán et al., 2011, San Miguel et al., 2005). Although the reasons for this high rate are not entirely clear, it is possible that this may be related to a 
combination of multiple factors, including differences in medical care resources, transplantation programs, implementation of infection control measures in hospitals, empirical antifungal therapy and prophylaxis for high-risk patients. Another possibility is that our series may not reflect the current trends, but the data from a prospective study held in Spain and recently published by Peman et al. support our data (Pemán et al., 2011, Pfaller \& Diekema, 2007) (see Table 7).

\begin{tabular}{|c|c|c|c|c|c|c|}
\hline \multirow[b]{2}{*}{ Country and period } & \multirow{2}{*}{$\begin{array}{c}\text { Total } \\
\text { number of } \\
\text { isolates }\end{array}$} & \multicolumn{5}{|c|}{$\%$ of total by most representative species } \\
\hline & & $\begin{array}{c}\text { C. } \\
\text { albicans }\end{array}$ & $\begin{array}{c}C . \\
\text { parapsilosis }\end{array}$ & $\begin{array}{c}C . \\
\text { tropicalis }\end{array}$ & $\begin{array}{c}\text { C. } \\
\text { glabrata }\end{array}$ & $\begin{array}{c}\text { C. } \\
\text { krusei }\end{array}$ \\
\hline USA 1992-1993 & 837 & 52 & 21 & 10 & 12 & 4 \\
\hline USA 1993-1995 & 79 & 56 & 15 & 10 & 15 & - \\
\hline USA 1995-1997 & 1593 & 46 & 14 & 12 & 20 & 2 \\
\hline USA 1995-1998 & 934 & 53 & 10 & 12 & 20 & 3 \\
\hline USA 1998-2000 & 935 & 45 & 13 & 12 & 24 & 2 \\
\hline USA 2001-2004 & 2773 & 51 & 14 & 7 & 22 & 2 \\
\hline USA 2008-2009 & 1354 & 48 & 17 & 10 & 18 & 2 \\
\hline Canada 1992-94 & 415 & 69 & 10 & 7 & 8 & 1 \\
\hline Latin America 1995-1996 & 145 & 37 & 25 & 24 & 4 & 1 \\
\hline Latin America 2001-2004 & 1565 & 50 & 16 & 20 & 7 & 2 \\
\hline Asia-Pacific 2001-2004 & 1344 & 56 & 16 & 14 & 10 & 2 \\
\hline Taiwan1994-2000 & 1095 & 50 & 14 & 21 & 12 & $<1$ \\
\hline Europe 1992-94 & 249 & 49 & 11 & 11 & 10 & 9 \\
\hline Europe 1997-99 & 2089 & 56 & 13 & 7 & 14 & 2 \\
\hline Europe 2001-2004 & 2515 & 60 & 12 & 9 & 10 & 5 \\
\hline Norway 1991-2003 & 1415 & 70 & 6 & 7 & 13 & 2 \\
\hline Denmark2003-2004 & 307 & 63 & 4 & 4 & 20 & 3 \\
\hline Spain 2002-2003 & 351 & 51 & 23 & 10 & 9 & 4 \\
\hline Spain 2001-2006 & 1997 & 47 & 19 & 10 & 12 & 5 \\
\hline Spain 2008-2009 & 984 & 49 & 21 & 13 & 11 & 2 \\
\hline Spain 2009-2010 & 1377 & 45 & 29 & 12 & 8 & 2 \\
\hline
\end{tabular}

Table 7. Summary of geographical differences in species distribution in Candida BSI isolates. (Adapted and modified from Pemán et al., 2001 and Pfaller \& Diekema, 2007).

Despite this fact, it seems that probably a combination of factors may have affected the overall rates of fungemia cases in Spain. The differences appeared in the average age of our patients when compared to other surveillance series from the United States (OstroskyZeichner et al., 2003, Pappas et al., 2003), are probably due to the high proportion of children in our study, especially in the Spanish hospitals located in the Southern part of the country (32\% of children in the Spanish hospitals from the Southern part of the country compared to $9 \%$ described in the study from the United States) (data not shown). Therefore, this condition reflects that there are great differences among patients of different geographical locations as it was mentioned in the introduction and the demographical composition and lastly the risk factors, could be very different from one population to another. (Table 7). In fact, the number of cases of invasive candidemia was not homogeneous across the country., the distribution of the clinical isolates obtained during the study period along four different 
geographical areas in Spain,. (North, Center, East and South). C. albicans covers almost half $(49.08 \%)$ of the global cases, remaining as the most frequently isolated specie, but the rates between the four different areas were not homogenous., for instance, in the Southern part of the country the rate of isolates of C. albicans (39.2\%) was similar to the one of C. parapsilosis $(37.4 \%)$.

Some studies have reported a shift in the etiology of candidemia reporting an increase of candidemia cases caused by non-albicans Candida species during the last decade (Colombo et al., 2006, Richet et al., 2002, Tortorano et al., 2004) (Table 7). Although C. albicans remain the most frequently isolated specie, reasons for the emergence of non-albicans species remain unclear, but some medical conditions may explain increasing incidence of candidemia due to non-albicans species. It has been noted in previous reports that infections due to $C$. tropicalis candidemia is associated with neoplasia and neutropenia (Komshian et al., 1989) and those attributable to $C$. parapsilosis are often associated with the presence of intravascular catheters and are not influenced by exposure to fluconazole or other antifungal agents (Clark et al., 2004, Girmenia et al., 1996, Levy et al., 1998, Sandven et al., 1998). The last situation, may us to consider C. parapsilosis as an exogenous pathogen and breaches of catheter care and of infection control practice should be investigated and revised within institutions where this species has become a common blood culture isolate.

The increasing incidence some of non-albicans Candida species with reduced susceptibility to azoles, such as C. glabrata, creates new therapeutic challenges and leads to another important question such as the influence of previous antifungal therapy in the development of non-albicans species candidemia. Recent studies, such as those published by Marr et al. and Tortorano et al. had addressed this question and showed interesting results about the association with previous exposure to azoles and the risk of development of fungemias due to C. krusei and / or C. glabrata (Marr et al., 2000, Tortorano et al., 2004). In fact, the differences in antifungal susceptibilities among isolates between different regions in Spain was almost entirely attributable to high-level resistance to azoles observed among C. glabrata and C. krusei isolates (Table 4).

We are not aware of these epidemiological changes mentioned in the paragraph above and our findings from our study are supportive of them. C. parapsilosis fungemia account for the large majority of non-albicans species (in the same manner that that been described for other European countries) and candidemia due to C. krusei is rare in Spain as it has been described in other series (Almirante et al., 2005, Alonso-Valle et al., 2003, Ostrosky-Zeichner et al., 2003, Pemán et al., 2002, Pemán et al., 2011, Tortorano et al., 2004). The explanation for this species distribution in Spain which is more or less similar to other Latin American countries is not clear and perhaps many factors are involved. However, this species distribution has got a great importance in the developing of therapeutic schemes and in the prevention of antifungal resistance.

While most non-albicans Candida species are associated with high fluconazole minimum inhibitory concentrations (MIC), C. parapsilosis is typically susceptible to most antifungals, although is associated with higher echinocandin MIC that vary between different agents. Moreover, the rate of persistently positive fungemia in patients treated with caspofungin was reported as almost double for C. parapsilosis versus other Candida species. Even more, if we consider clinical patients at risk of suffering a candidemia episode, such as 
immunocompromised patients, where clinical responses are poorer the picture is not good. Summarizing, we are concerned about the use of echinocandins alone based on the identification of non-albicans Candida specie. Grouping these agents into one treatment scheme is difficult due to the variability not only in the susceptibility of the isolates, as well as the microbiological responses seen between different echinocandins.

Regarding the susceptibility of the studied isolates, antifungal resistance was an infrequent finding in our study and was restricted to a few isolates, and none of them were resistant to amphotericin B. This condition is similar to the findings published in three recent studies (Almirante et al., 2005, Messer et al., 2009, Pemán et al., 2011). Our proportion of fluconazole-resistant isolates $(6.32 \%)$ was low, similarly to the rate observed with Spanish (Almirante et al., 2005, Pemán et al., 2011) European (5.2\%) and North American isolates (6.6\%) (Messer et al., 2009, Richardson \& Lass-Flörl et al., 2008) (see Table 7). Mixing the ideas exposed above we can argue that the differences in the activity and susceptibility of the antifungal compounds studied suggest that azole drugs and echinocandins have got a complementary susceptibility profile. While azoles has got excellent in vitro activity to $C$. albicans, C. parapsilosis and C. tropicalis bloodstream isolates, echinocandins showed excellent activity against C. glabrata and C. krusei which are are associated with higher azole MICs. On the contrary, species with high MICs to echinocandins such as C. parapsilosis and C. guilliermondii showed excellent activity to azole agents. (Table 8).

\begin{tabular}{cccccc}
\hline \multirow{2}{*}{ Specie of Candida a } & \multicolumn{5}{c}{ Susceptibility to antifungal agent } \\
\cline { 2 - 6 } & Amphotericin B & Fluconazole & Voriconazole & Caspofungin & Anidulafungin \\
\hline C. albicans & S & S & S & S & S \\
C. parapsilosis & S & S & S & S - I & S - I \\
C. glabrata & S - NS & S - SDD - R & S - NS & S & S \\
C. tropicalis & S & S & S - NS & S & S \\
C. krusei & S & R & S & S & S \\
\hline
\end{tabular}

a S, susceptible; NS, non-susceptible (intermediate for CLSI M27-A2 clinical breakpoints); SDD, sensitive dose-dependent; $R$, resistant.

$\mathrm{b}$ The clinical breakpoints adopted in this table are those reflected in the CLSI M27-A2 methodology. No new clinical breakpoints or epidemiological cut-offs were used, in order to make the data comparable to the one reflected in our work.

Table 8. Summary of commonly associated in-vitro susceptibility profiles for Candida spp. BSI isolates. (Adapted and modified from Richardson \& Lass-Flörl, 2008) a, b

These ideas are of great importance because previous exposure to fluconazole was a strong and independent factor associated with candidemia caused by fluconazole non-susceptible isolates as it had been reported previously by Marr et al. and Lin and colleagues and higher voriconazole MICs tended to be associated with prior exposure to fluconazole. Although these obtained results are statistically significant, they must be taken with some caution because the low resistant proportion of isolates in our study. However, they depict a situation of concern and illustrate the potential problem of cross-resistance between azoles with a direct impact in treatment failure and the outcome of the patient. Moreover, the potential for voriconazole resistant $C$. glabrata to emerge as a threat in people receiving voriconazole therapy and or prophylaxis has been raised in reports of breakthrough infections (Imhof et al., 2004, Pfaller et al., 2004). 
Despite these concerning matters exposed above, voriconazole was the azole which exhibited the best in vitro antifungal activity in our study, and only one of six fluconazoleresistant isolates was cross-resistant to voriconazole. The combination of a third generation azole such as voriconazole or posaconazole with an echinocandin could be of benefit for some patients, especially in those with persistent candidemia.

The crude mortality rate observed in our study was similar to that reported in other series (Almirante et al., 2005, Colombo et al., 2006, Gudlaugsson et al., 2003, Pappas et al., 2003, Pfaller et al., 2004). Adults had higher mortality rates than pediatric patients $(24.10 \%$ to $16 \%$ ). Similar to other reports, patients with C. parapsilosis candidemia had the lowest death rates (Nucci et al., 1998, Pappas et al., 2003).

Summarizing, the epidemiological and susceptible data described along the text, document important differences and similarities in the epidemiology of candidemia in Spain compared to updated reports from other countries. This report shows that candidemia is a source of significant morbidity and mortality with high associated healthcare costs. Although our high rates of candidemia may be related to many factors, reasons for them are not clear and further study is necessary. Determining them may lead to identify potential measures that can help in disease prevention. In addition, our data support that fluconazole nonsusceptibility could be associated with prior fluconazole exposure and suggest that such exposure could lead to other new azoles cross-resistance and complicate the clinical outcome of some patients.

\section{Acknowledgments}

To the Spanish Candidemia Surveillance Group composed in this study, by 40 hospitals distributed in four diferents Areas of Spain, North, Center, East and South.

\section{References}

[1] Al-Jasser, A. M., and N. A. Elkhizzi. 2004. Distribution of Candida species among bloodstream isolates. Saudi Med. J. 25:566-569.

[2] Almirante, B., D. Rodriguez, B. J. Park, M. Cuenca-Estrella, A. M. Planes, M. Almela, J. Mensa, F. Sanchez, J. Ayats, M. Gimenez, P. Saballs, S. K. Fridkin, J. Morgan, J. L. Rodriguez-Tudela, D. W. Warnock, and A. Pahissa. 2005. Epidemiology and predictors of mortality in cases of Candida bloodstream infection: results from population-based surveillance, Barcelona, Spain, from 2002 to 2003. J. Clin. Microbiol. 43:1829-1835.

[3] Alonso-Valle, H., O. Acha, J. D. Garcia-Palomo, C. Farinas-Alvarez, C. FernandezMazarrasa, and M. C. Farinas. 2003. Candidemia in a tertiary care hospital: epidemiology and factors influencing mortality. Eur. J. Clin. Microbiol. Infect. Dis. 22:254-257.

[4] Antunes, A. G., A. C. Pasqualotto, M. C. Diaz, P. A. d'Azevedo, and L. C. Severo. 2004. Candidemia in a Brazilian tertiary care hospital: species distribution and antifungal susceptibility patterns. Rev. Inst. Med. Trop. Sao Paulo 46:239-241.

[5] Asmundsdottir, L. R., H. Erlendsdottir, and M. Gottfredsson. 2002. Increasing incidence of candidemia: results from a 20-year nationwide study in Iceland. J. Clin. Microbiol. 40:3489-3492. 
[6] Banerjee, S. N., T. G. Emori, D. H. Culver, R. P. Gaynes, W. R. Jarvis, T. Horan, J. R. Edwards, J. Tolson, T. Henderson, W. J. Martone, et al. 1991. Secular trends in nosocomial primary bloodstream infections in the United States, 1980-1989. Am. J. Med. 91:86S-89S.

[7] Berenguer J, M Buck, F Witebsky, et al. 1993. Lysis-centrifugation blood cultures in the detection of tissue-proven invasive candidiasis. disseminated versus single-organ infection. Diagn Microbiol Infect Dis. 7:103-109.)

[8] Blumberg, H. M., W. R. Jarvis, J. M. Soucie, J. E. Edwards, J. E. Patterson, M. A. Pfaller, M. S. Rangel-Frausto, M. G. Rinaldi, L. Saiman, R. T. Wiblin, R. P. Wenzel, et al. 2001. Risk factors for candidal bloodstream infections in surgical intensive care unit patients: the NEMIS prospective multicenter study. Clin. Infect. Dis. 33:177-186.

[9] Clark, T. A., S. A. Slavinski, J. Morgan, T. Lott, B. A. Arthington-Skaggs, M. E. Brandt, R. M. Webb, M. Currier, R. H. Flowers, S. K. Fridkin, and R. A. Hajjeh. 2004. Epidemiologic and molecular characterization of an outbreak of Candida parapsilosis bloodstream infections in a community hospital. J. Clin. Microbiol. 42:4468-4472.

[10] L. Colombo, M. Nucci, B. J. Park, S. A. Nouér, B. Arthington-Skaggs, D. A. da Matta, D. Warnock, and J. Morgan for the Brazilian Network Candidemia Study. 2006. Epidemiology of candidemia in Brazil: a nationwide sentinel surveillance of candidemia in eleven medical centers J. Clin. Microbiol. 44:2816-2823.

[11] Costa, S. F., I. Marinho, E. A. Araujo, A. E. Manrique, E. A. Medeiros, and A. S. Levin. 2000. Nosocomial fungaemia: a 2-year prospective study. J. Hosp. Infect. 45:69-72.

[12] Diekema, D. J., S. A. Messer, A. B. Brueggemann, S. L. Coffman, G. V. Doern, L. A. Herwaldt, and M. A. Pfaller. 2002. Epidemiology of candidemia: 3-year results from the emerging infections and the epidemiology of Iowa organisms study. J. Clin. Microbiol. 40:1298-1302.

[13] Doczi, I., E. Dosa, E. Hajdu, and E. Nagy. 2002. Aetiology and antifungal susceptibility of yeast bloodstream infections in a Hungarian university hospital between 1996 and 2000. J. Med. Microbiol. 51:677-681.

[14] Fraser, V. J., M. Jones, J. Dunkel, S. Storfer, G. Medoff, and W. C. Dunagan. 1992. Candidemia in a tertiary care hospital: epidemiology, risk factors, and predictors of mortality. Clin. Infect. Dis. 15:414-421.

[15] Garbino, J., L. Kolarova, P. Rohner, D. Lew, P. Pichna, and D. Pittet. 2002. Secular trends of candidemia over 12 years in adult patients at a tertiary care hospital. Medicine (Baltimore) 81:425-433.

[16] Girmenia, C., P. Martino, B. F. De, G. Gentile, M. Boccanera, M. Monaco, G. Antonucci, and A. Cassone. 1996. Rising incidence of Candida parapsilosis fungemia in patients with hematologic malignancies: clinical aspects, predisposing factors, and differential pathogenicity of the causative strains. Clin. Infect. Dis. 23:506-514.

[17] Gudlaugsson, O., S. Gillespie, K. Lee, B. J. Vande, J. Hu, S. Messer, L. Herwaldt, M. Pfaller, and D. Diekema. 2003. Attributable mortality of nosocomial candidemia, revisited. Clin. Infect. Dis. 37:1172-1177. 19. Hsueh, P. R., L. J. Teng, P. C. Yang, S. W. Ho, and K. T. Luh. 2002. Emergence of nosocomial candidemia at a teaching hospital in Taiwan from 1981 to 2000: increased susceptibility of Candida species to fluconazole. Microb. Drug Resist. 8:311-319. 
[18] Imhof, A., S. A. Balajee, D. N. Fredricks, J. A. Englund, and K. A. Marr. 2004. Breakthrough fungal infections in stem cell transplant recipients receiving voriconazole. Clin. Infect. Dis.39:743-746.

[19] Kao, A. S., M. E. Brandt, W. R. Pruitt, L. A. Conn, B. A. Perkins, D. S. Stephens, W. S. Baughman, A. L. Reingold, G. A. Rothrock, M. A. Pfaller, R. W. Pinner, and R. A. Hajjeh. 1999. The epidemiology of candidemia in two United States cities: results of a population-based active surveillance. Clin. Infect. Dis. 29:1164-1170.

[20] Komshian, S. V., A. K. Uwaydah, J. D. Sobel, and L. R. Crane. 1989. Fungemia caused by Candida species and Torulopsis glabrata in the hospitalized patient: frequency, characteristics, and evaluation of factors influencing outcome. Rev. Infect. Dis. 11:379-390.

[21] Levy, I., L. G. Rubin, S. Vasishtha, V. Tucci, and S. K. Sood. 1998. Emergence of Candida parapsilosis as the predominant species causing candidemia in children. Clin. Infect. Dis. 26:1086-1088.

[22] Luzzati, R., G. Amalfitano, L. Lazzarini, F. Soldani, S. Bellino, M. Solbiati, M. C. Danzi, S. Vento, G. Todeschini, C. Vivenza, and E. Concia. 2000. Nosocomial candidemia in non-neutropenic patients at an Italian tertiary care hospital. Eur. J. Clin. Microbiol. Infect. Dis. 19:602-607.

[23] Marchetti, O., J. Bille, U. Fluckiger, P. Eggimann, C. Ruef, J. Garbino, T. Calandra, M. P. Glauser, M. G. Tauber, and D. Pittet. 2004. Epidemiology of candidemia in Swiss tertiary care hospitals: secular trends, 1991-2000. Clin. Infect. Dis. 38:311-320.

[24] Marr, K. A., K. Seidel, T. C. White, and R. A. Bowden. 2000. Candidemia in allogeneic blood and marrow transplant recipients: evolution of risk factors after the adoption of prophylactic fluconazole. J. Infect. Dis. 181:309-316.

[25] Messer S.A. Moet G.J. Kirvy J. T. and Jones R.N. 2009. Activity of contemporary antifungal agents, including the novel echinocandin anidulafungin, tested against Candida spp. Cryptococcus spp. and Aspergillus spp.: Report from the SENTRY antimicrobial surveillance program (2006 to 2007) J. Clin. Microbiol. 47 (6): 19421946.

[26] Morgan, J., M. I. Meltzer, B. D. Plikaytis, A. N. Sofair, S. Huie-White, S. Wilcox, L. H. Harrison, E. C. Seaberg, R. A. Hajjeh, and S. M. Teutsch. 2005. Excess mortality, hospital stay, and cost due to candidemia: a case-control study using data from population-based candidemia surveillance. Infect. Control Hosp. Epidemiol. 26:540547.

[27] National Committee for Clinical Laboratory Standards. 2002. Reference method for broth dilution antifungal susceptibility testing of yeasts; approved standard, 2nd ed. Document M27-A2. National Committee For Clinical Laboratory Standards, Wayne, Pa.

[28] Nguyen, M. H., C. J. Clancy, V. L. Yu, Y. C. Yu, A. J. Morris, D. R. Snydman, D. A. Sutton, and M. G. Rinaldi. 1998. Do in vitro susceptibility data predict the microbiologic response to amphotericin B? Results of a prospective study of patients with Candida fungemia. J. Infect. Dis. 177:425-430.

[29] Nucci, M., A. L. Colombo, F. Silveira, R. Richtmann, R. Salomao, M. L. Branchini, and N. Spector. 1998. Risk factors for death in patients with candidemia. Infect. Control Hosp. Epidemiol. 19:846-850. 
[30] Ostrosky-Zeichner, L., J. H. Rex, P. G. Pappas, R. J. Hamill, R. A. Larsen, H. W. Horowitz, W. G. Powderly, N. Hyslop, C. A. Kauffman, J. Cleary, J. E. Mangino, and J. Lee. 2003. Antifungal susceptibility survey of 2,000 bloodstream Candida isolates in the United States. Antimicrob. Agents Chemother. 47:3149-3154.

[31] Pappas, P. G., J. H. Rex, J. Lee, R. J. Hamill, R. A. Larsen, W. Powderly, C. A. Kauffman, N. Hyslop, J. E. Mangino, S. Chapman, H. W. Horowitz, J. E. Edwards, and W. E. Dismukes. 2003. A prospective observational study of candidemia: epidemiology, therapy, and influences on mortality in hospitalized adult and pediatric patients. Clin. Infect. Dis. 37:634-643.

[32] Pemán J, Cantón E, Orero A, Viudes A, Frasquet J, Gobernado M. 2002. Epidemiology of candidemia in Spain - Multicenter study. Rev Iberoam Micol. 19(1):30-35.

[33] Pemán J, Cantón E, Miñana JJ, Florez JA, Echeverria J, Ortega DN, Alarcón JM, Fontanals D, Sard BG, Moreno BB, Torroba L, Ayats J, Pérez MÁ, Fernández MA, Reus FS, Natal IF, García GR, Ezpeleta G, Martín-Mazuelos E, Iglesias I, Rezusta A, de Ocariz IR, Nieto AG; el Grupo de Estudio FUNGEMYCA. 2011. Changes in the epidemiology of fungaemia and fluconazole susceptibility of blood isolates during the last 10 years in Spain: results from the FUNGEMYCA study]. Rev Iberoam Micol. Apr-Jun;28(2):91-9

[34] Pfaller, M. A., R. N. Jones, G. V. Doern, H. S. Sader, R. J. Hollis, and S. A. Messer for the SENTRY Participant Group. 1998. International surveillance of bloodstream infections due to Candida species: frequency of occurrence and antifungal susceptibilities of isolates collected in 1997 in the United States, Canada, and South America for the SENTRY Program. J. Clin. Microbiol. 36:1886-1889.

[35] Pfaller, M. A., S. A. Messer, L. Boyken, S. Tendolkar, R. J. Hollis, and D. J. Diekema. 2004. Geographic variation in the susceptibilities of invasive isolates of Candida glabrata to seven systemically active antifungal agents: a global assessment from the ARTEMIS Antifungal Surveillance Program conducted in 2001 and 2002. J. Clin. Microbiol. 42:3142-3146.

[36] Pfaller M. A. and D. J. Diekema. 2007. Epidemiology of invasive candidiasis: a persistent public health problem. Clin. Microbiol. Rev. 20: 133 -163.

[37] Richardson M. And C. Lass-Flörl. 2008. Changing epidemiology of systemic fungal infections. Clin. Microbiol. Infect. 14 (Suppl. 4): 5-24.

[38] Richet, H., P. Roux, C. C. Des, Y. Esnault, and A. Andremont. 2002. Candidemia in French hospitals: incidence rates and characteristics. Clin. Microbiol. Infect. 8:405412.

[39] Sandven, P., L. Bevanger, A. Digranes, P. Gaustad, H. H. Haukland, and M. Steinbakk. 1998. Constant low rate of fungemia in Norway, 1991 to 1996. The Norwegian Yeast Study Group. J. Clin. Microbiol. 36:3455-3459.

[40] San Miguel, L. G., J. Cobo, E. Otheo, A. Sanchez-Sousa, V. Abraira, and S. Moreno. 2005. Secular trends of candidemia in a large tertiary-care hospital from 1988 to 2000: emergence of Candida parapsilosis. Infect. Control Hosp. Epidemiol. 26:548-552.

[41] Silva, V., M. C. Diaz, and N. Febre. 2004. Invasive fungal infections in Chile: a multicenter study of fungal prevalence and susceptibility during a 1-year period. Med. Mycol. 42:333-339.

[42] Tortorano, A. M., E. Biraghi, A. Astolfi, C. Ossi, M. Tejada, C. Farina, S. Perin, C. Bonaccorso, C. Cavanna, A. Raballo, and A. Grossi. 2002. European Confederation 
of Medical Mycology (ECMM) prospective survey of candidaemia: report from one Italian region. J. Hosp. Infect. 51:297-304.

[43] Tortorano, A. M., J. Peman, H. Bernhardt, L. Klingspor, C. C. Kibbler, O. Faure, E. Biraghi, E. Canton, K. Zimmermann, S. Seaton, and R. Grillot. 2004. Epidemiology of candidaemia in Europe: results of 28-month European Confederation of Medical Mycology (ECMM) hospital-based surveillance study. Eur. J. Clin. Microbiol. Infect. Dis. 23:317-322.

[44] Trick, W. E., S. K. Fridkin, J. R. Edwards, R. A. Hajjeh, and R. P. Gaynes. 2002. Secular trend of hospital-acquired candidemia among intensive care unit patients in the United States during 1989-1999. Clin. Infect. Dis. 35: 627-630.

[45] Viudes, A., J. Peman, E. Canton, P. Ubeda, J. L. Lopez-Ribot, and M. Gobernado. 2002. Candidemia at a tertiary-care hospital: epidemiology, treatment, clinical outcome and risk factors for death. Eur. J. Clin. Microbiol. Infect. Dis. 21:767-774.

[46] Voss, A., J. A. Kluytmans, J. G. Koeleman, L. Spanjaard, C. M. Vandenbroucke-Grauls, H. A. Verbrugh, M. C. Vos, A. Y. Weersink, J. A. Hoogkamp-Korstanje, and J. F. Meis. 1996. Occurrence of yeast bloodstream infections between 1987 and 1995 in five Dutch university hospitals. Eur. J. Clin. Microbiol. Infect. Dis. 15:909-912. 


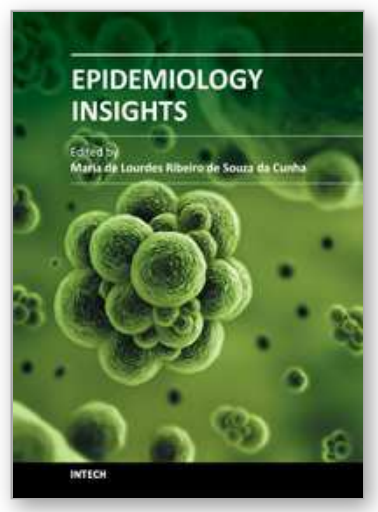

\author{
Epidemiology Insights \\ Edited by Dr. Maria De Lourdes Ribeiro De Souza Da Cunha
}

ISBN 978-953-51-0565-7

Hard cover, 396 pages

Publisher InTech

Published online 20, April, 2012

Published in print edition April, 2012

This book represents an overview on the diverse threads of epidemiological research, brings together the expertise and enthusiasm of an international panel of leading researchers to provide a state-of-the art overview of the field. Topics include the epidemiology of dermatomycoses and Candida spp. infections, the epidemiology molecular of methicillin-resistant Staphylococcus aureus (MRSA) isolated from humans and animals, the epidemiology of varied manifestations neuro-psychiatric, virology and epidemiology, epidemiology of wildlife tuberculosis, epidemiologic approaches to the study of microbial quality of milk and milk products, Cox proportional hazards model, epidemiology of lymphoid malignancy, epidemiology of primary immunodeficiency diseases and genetic epidemiology family-based. Written by experts from around the globe, this book is reading for clinicians, researchers and students, who intend to address these issues.

\title{
How to reference
}

In order to correctly reference this scholarly work, feel free to copy and paste the following:

R. Cisterna, G. Ezpeleta and O. Tellería (2012). Epidemiology of Bloodstream Candida spp. Infections Observed During a Surveillance Study Conducted in Spain, Epidemiology Insights, Dr. Maria De Lourdes Ribeiro De Souza Da Cunha (Ed.), ISBN: 978-953-51-0565-7, InTech, Available from: http://www.intechopen.com/books/epidemiology-insights/epidemiology-of-bloodstream-candida-spp-infectionsobserved-during-a-nationwide-sentinel-surveillanc

\section{INTECH}

open science | open minds

\section{InTech Europe}

University Campus STeP Ri

Slavka Krautzeka 83/A

51000 Rijeka, Croatia

Phone: +385 (51) 770447

Fax: +385 (51) 686166

www.intechopen.com

\section{InTech China}

Unit 405, Office Block, Hotel Equatorial Shanghai

No.65, Yan An Road (West), Shanghai, 200040, China

中国上海市延安西路65号上海国际贵都大饭店办公楼 405 单元

Phone: +86-21-62489820

Fax: $+86-21-62489821$ 
(C) 2012 The Author(s). Licensee IntechOpen. This is an open access article distributed under the terms of the Creative Commons Attribution 3.0 License, which permits unrestricted use, distribution, and reproduction in any medium, provided the original work is properly cited. 